ORIGINAL ARTICLE

\title{
Sexually inappropriate behaviour in demented elderly people
}

\author{
K Alagiakrishnan, D Lim, A Brahim, A Wong, A Wood, A Senthilselvan, W T Chimich, L Kagan
}

Postgrad Med J 2005;81:463-466. doi: 10.1136/pgmi.2004.028043

See end of article for authors' affiliations

.....................

Correspondence to:

Dr K Alagiakrishnan,

1257, Glenrose

Rehabilitation Hospital,

!0230-111 Ave NW,

Edmonton, Canada, $\mathrm{AB}$

T5G 0B7; kalagiak@cha.

ab.ca

Submitted 23 August 2004

Accepted

17 November 2004 iology, and treatment profile of abnormal sexual behaviour in Aim: To determine the prevalence, aetiology, and
subjects with dementia in psychogeriatric practices.

Methods: A retrospective cross sectional study was conducted in a long term care psychiatry consultation service, community based geriatric psychiatry service, and an inpatient dementia behavioural unit in Edmonton, Canada.

Results: Forty one subjects (1.8\%) had sexually inappropriate behaviour. Of those cognitively impaired subjects with sexually inappropriate behaviour, 20 (48.8\%) were living in nursing homes and the rest, 21 $(51.2 \%)$ in the community. Of these subjects, $53.7 \%$ had vascular dementia, $22 \%$ had Alzheimer's, and $9.8 \%$ had mild cognitive impairment. History of alcohol misuse and psychosis were reported in $14.6 \%$ and $9.8 \%$ of subjects respectively. Twenty seven (65.7\%) had verbally inappropriate behaviour and 36 (87.8\%) had physically inappropriate behaviour. In this study, verbally inappropriate behaviour was more commonly seen in the community sample $(81 \%)$ than in the nursing home sample $(50 \%)(p=0.04)$. Behavioural treatment was also more commonly seen in the community sample (81\%) than in the nursing home sample (45\%) $(p=0.01)$.

Conclusion: In this study sexually inappropriate behaviour was seen in all stages of dementia, more commonly associated with subjects of vascular aetiology, and is as commonly seen in community dwelling subjects with dementia as in nursing home subjects.
A ggression and agitation are common problems seen in the geriatric population with moderate to severe stages of impaired cognition, and especially in long term care patients with dementia. The prevalence of physically aggressive behaviour increases with the progression of dementia, and it often heralds a poor prognosis. ${ }^{12}$ Behavioural disorders, which include pacing, hitting, sexually inappropriate behaviour, agitation, or aggression, represent a considerable source of stress to patients, families, and caregivers.

Sexuality is part of human nature throughout life. Being elderly and sick does not necessarily mean that there is a decline in sexual desire. Patients with dementia may become sexually disinhibited as cognitive deficits progress. Caregivers who are taking care of demented elderly people should expect sexual behaviours to occur and they should be ready to respond appropriately. Sexually inappropriate behaviour can include verbal or physical abnormal behaviour. The physical inappropriate behaviour includes sexual touching, fondling, disrobing, masturbation, and sexual advances.

Abnormal sexual behaviour in the long term care setting includes unwanted sexual advances such as climbing into bed with other residents in a nursing home or actual attempts of intercourse and aberrant sexual behaviour such as sexual aggression. Sexual aggression manifesting itself as hypersexuality may also be attributable to drugs, psychosis, mania, and various neurological disorders including frontal lobe lesions. ${ }^{3}$ Inappropriate sexual behaviour in the demented person can be difficult to assess because the person may not be able to explain their actions. While most sexually aggressive behaviour/inappropriate sexual behaviour occurs in the moderate to severe stages of Alzheimer's dementia, it may also be seen in early stages of fronto-temporal dementia because of the lack of insight and disinhibition.

It may herald the worsening of dementia with executive dyscontrol, sexual disinhibition, and tendency to impulsive behaviour, particularly if there is impairment of frontal subcortical circuits. These behaviours can compromise the care of nursing home residents and the safety of the staff. The predisposition of elderly patients with dementia to psychotropic toxicity further complicates the management of such aggressive behaviour. There are several possible causes of inappropriate repetitive sexual behaviour in a patient with dementia. The purpose of this study is to find out the prevalence of sexual abnormal behaviour in subjects with dementia at psychogeriatric practices in Edmonton and to identify the aetiology, type of presentation, and treatment in these subjects.

\section{METHODS}

This is a retrospective cross sectional study at three centres in Edmonton-the long term care psychiatric consulting services, community based geriatric psychiatry, and inpatient dementia behavioural unit. All charts $(n=2278)$ (community based geriatric psychiatry-350, inpatient dementia behavioural unit-274, and the rest from long term care

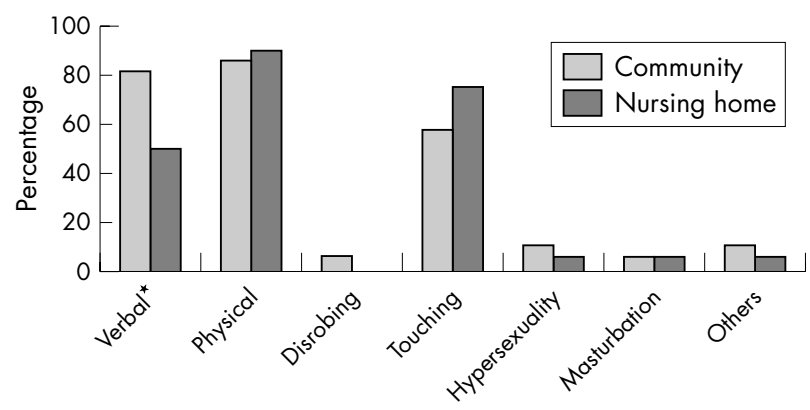

Figure1 Presentation of sexually inappropriate behaviour. *Significant $(p=0.039)$. 
Table 1 Patient characteristics with sexually inappropriate behaviour in demented elderly patients

\begin{tabular}{|c|c|c|}
\hline & Numbers & Percentages \\
\hline \multicolumn{3}{|l|}{ Age } \\
\hline $65-80$ & 24 & 58.5 \\
\hline$>80$ & 17 & 41.5 \\
\hline \multicolumn{3}{|l|}{ Sex } \\
\hline Male & 38 & 92.7 \\
\hline Female & 3 & 7.3 \\
\hline \multicolumn{3}{|l|}{ Living situation } \\
\hline Home & 11 & 26.8 \\
\hline Supportive living & 10 & 24.4 \\
\hline Nursing home & 20 & 48.8 \\
\hline \multicolumn{3}{|l|}{ Types of services } \\
\hline Community psychiatry & 14 & 34.1 \\
\hline Long term care psychiatry & 16 & 39.0 \\
\hline Inpatient behavioural & 11 & 26.8 \\
\hline \multirow{2}{*}{\multicolumn{3}{|c|}{ dementia unit }} \\
\hline & & \\
\hline Mild cognitive impairment & 4 & 9.8 \\
\hline Alzheimer's & 9 & 22.0 \\
\hline Vascular & 22 & 53.6 \\
\hline Alcohol related & 5 & 12.2 \\
\hline Others & 1 & 2.4 \\
\hline \multicolumn{3}{|l|}{ Types of psychiatric issues } \\
\hline Psychosis & 4 & 9.8 \\
\hline Mania & 1 & 2.4 \\
\hline Alcohol misuse & 6 & 14.6 \\
\hline Substance misuse & 1 & 2.4 \\
\hline \multicolumn{3}{|l|}{ Neurological problems } \\
\hline Parkinson's & 3 & 7.3 \\
\hline Stroke & 16 & 39.0 \\
\hline
\end{tabular}

psychiatry consulting services) in the years 2001 and 2002 with a diagnosis of dementia were included in the study and screened for documentation of sexually abnormal behaviour. Diagnosis of dementia was made by DSM IV criteria. In this study, sexually inappropriate behaviour was defined as subjects having verbal or physical aberrant sexual behaviours, or both. Physically inappropriate behaviours include unwanted sexual advances like touching inappropriately or fondling and abnormal sexual behaviour like public masturbation or disrobing or hypersexuality and actual attempts of intercourse. Verbal inappropriate behaviours include foul or bad or embarrassing language or sexual remarks. Subjects who did not have the documentation of sexual inappropriate behaviour and deceased patients whose charts were not available were excluded from the study. Demographic information, details about sexually abnormal behaviour, and management were obtained. Ethics committee and site

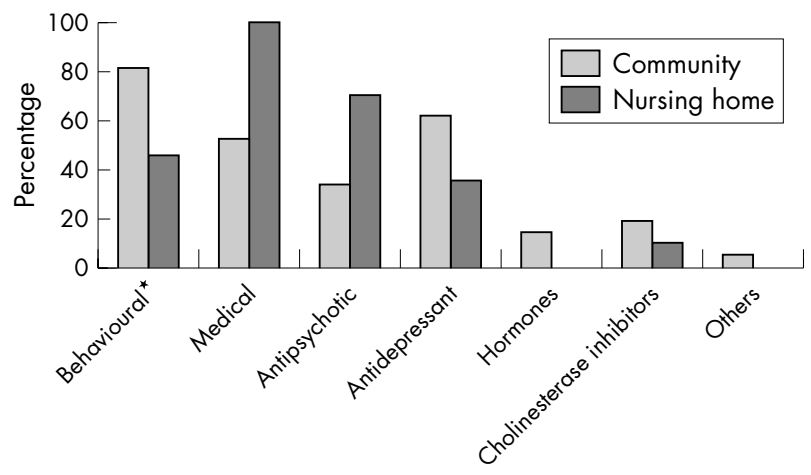

Figure 2 Management of sexually inappropriate behaviour. *Significant $(p=0.019)$. administrative approval were obtained from all the centres participating in the study.

\section{Statistical analyses}

Continuous variables were described with means and standard deviations. Frequencies and percentages were used to describe categorical data. We used $\chi^{2}$ statistics for two by two tables to test the statistically significant differences between two proportions.

\section{RESULTS}

In this study, the prevalence of sexually inappropriate behaviour was $1.8 \%$. Among the 41 cognitively impaired subjects with sexual inappropriate behaviour, age ranged from 65 to 92 (mean (SD) 78.3 (7.5)). There were more men $(92.7 \%)$ than women $(7.3 \%)$. Twenty $(48.8 \%)$ were living in nursing homes and the rest $(51.2 \%)$ in the community. In the study, almost the same proportion of subjects was seen by community psychiatry $(33.1 \%)$, long term care psychiatry $(39 \%)$, and the inpatient behavioural unit $(27 \%)$.

Of these subjects, $54 \%$ had vascular dementia, $22 \%$ had Alzheimer's, and 9.8\% had mild cognitive impairment. Mean score on the Folstein mini-mental status examination in these subjects was 18 (range 12-28). Alcohol misuse and psychosis were reported in $14.6 \%$ and $9.8 \%$ of subjects respectively (table 1 ). Twenty seven $(65.7 \%$ ) had verbally inappropriate behaviour and $36(87.8 \%)$ had physically inappropriate behaviour. Among those with physically inappropriate behaviour, 27 (65.7\%) had documentation of inappropriate touching and three $(7.3 \%)$ had hypersexuality. Twenty two $(53.7 \%)$ had both verbal and physical inappropriate behaviour. Verbally inappropriate behaviour was more commonly seen in the community sample $(81 \%)$ than in $\mathrm{NH}$ sample $(50 \%)(\mathrm{p}=0.04)$ (fig 1$)$.

Twenty six (63.4\%) had behavioural treatment, 18 (43.8\%) were taking antipsychotics, three $(7.3 \%)$ were receiving hormonal therapy, and six (14.6\%) were taking cholinesterase inhibitors. Behavioural treatment was more commonly seen in the community sample $(81 \%)$ than in $\mathrm{NH}$ sample $(45 \%)(\mathrm{p}=0.01)($ fig 2$)$.

\section{DISCUSSION}

Sexually inappropriate behaviour is generally known to be more common in men than in women. Our results were similar to other study results in that this type of behaviour is more commonly seen in male subjects (93\%). Sexually inappropriate behaviour can be seen in different settings ${ }^{4}$ although more commonly reported in an institutional setting. ${ }^{5}$ Our study shows this challenging behaviour was seen in both community dwelling subjects with dementia as well as in nursing home subjects. Moreover our study also points out that $51 \%$ of the sexually inappropriate subjects were living and being managed within the community.

Previous studies found that higher prevalence of inappropriate sexual behaviour was found in severely demented patients. $^{79}$ Sexual activity can increase in association with progression of dementia. This can result in unreasonable and exhausting demands on sexual partners at unacceptable times and inappropriate places. Occasionally, physical aggression may result if these needs are not met. These patients are among the most difficult to manage and present a tremendous challenge to the physicians. In our study, sexually inappropriate behaviour was seen even in the stage of mild cognitive impairment $(9.8 \%)$. Previous studies had reported that the prevalence of this behaviour ranges from $2.9 \%$ to $7 \%$ of Alzheimer's dementia subjects. ${ }^{8}{ }^{9}$ In this study, this behaviour was associated more commonly in vascular dementia subjects group (54\%) rather than Alzheimer's subjects group $(22 \%)$. To our knowledge, our study is the 
first one to show that this behaviour is more commonly associated with vascular demented patients. Only 13 subjects in this study had the clock drawing test done and all these were abnormal drawings, suggesting executive dysfunction may play a part in this behaviour

Sexually inappropriate behaviour can be very upsetting to caregivers. A lot of what is seen in the demented elderly is really sexually ambiguous behaviour such as disrobing, and involves no sexual arousal. It is caused by disorganisation secondary to cognitive impairment. On the other hand, a repetitive sexually aggressive behaviour may be attributable to a compulsive-impulsive range of symptoms and disorders. ${ }^{3}$ Like other repetitive and disruptive behaviours, the constant inappropriate touching behaviour of opposite sex may be postulated to fall within this range. The most common inappropriate physical behaviour seen in our study subjects was also inappropriate touching of the opposite sex $(87.8 \%)$, most commonly the homecare-caregivers.

When assessing abnormal behaviour it is necessary to take behavioural history, which should specify the type of abnormal behaviour, frequency of occurrence, duration of the symptoms, and settings that produce the symptoms. Always look for indicators of tendencies towards sexually inappropriate behaviour such as jokes with sexual innuendos. In some patients these do not necessarily represent an intent towards sexual aggressive behaviour as they may not comprehend the meaning of their own words.

Findings from this descriptive study and literature review provide some useful insights regarding management of these behaviours. Most of the treatments suggested for aggressiveness in dementia have only marginal benefit for controlling sexual aggressiveness. Inappropriate sexual behaviours are often better managed by non-pharmacological means, as patients may be less responsive to psychoactive therapies. Behavioural therapy includes redirecting the behaviour verbally or if necessary physically. Firmly but gently identify the behaviour and point out that it is unacceptable. Remind the subject who you are, especially if the resident is confused. Exposing and fondling genitals and public masturbation may be minimised by choosing clothing that opens in the back and by assigning manual activities such as folding towels. If behavioural interventions fail, pharmacological therapy may be necessary. These include drugs such as the newer neuroleptics like risperidone, olanzapine, clozapine, and quetiapine, and the selective serotonin reuptake inhibitors (SSRIs), trazadone, buspirone, lithium and valproate. ${ }^{10} 11$ Serotonin has a critical role in mood modulation and impulse control. This explains, in part, the response of obsessivecompulsive disorders to various proserotonergic agents. The role of SSRIs in the treatment of obsessive-compulsive disorders is well established. ${ }^{3}$ The different inhibitory effects of various SSRIs on the reuptake of serotonin, norepinephrine, and dopamine is well known. Other possible mechanisms for the effectiveness of SSRI may be attributable to the antilibidinal effects of SSRIs. ${ }^{3}$

Other drugs that have been used with varying success in the treatment of sexual aggression include antiandrogens, oestrogens, and gonadotropin releasing hormone analogues. Sexually aggressive behaviour in men has been treated with antiandrogens, oestrogen, and medroxy progesterone acetate. $^{12}{ }^{13}$ The effectiveness of these drugs have been reported mainly in case reports, and in most instances in younger patients. Medroxyprogesterone (Amen, Cycrin, DepoProvera) and related hormonal agents have been used for the treatment of intrusive disinhibited sexual behaviour. A randomised controlled trial is needed to assess the true efficacy of these agents in the management of sexually aggressive behaviours. One study also points out that cimetidine, which has antiandrogen properties, decreases libido and hypersexual behaviour without serious side effects. ${ }^{14}$ Cholinesterase inhibitors have also been found to be effective as a single therapy for this behaviour. ${ }^{15}$

In our study, behavioural treatment was seen in $63.4 \%$ of subjects. Forty four per cent were taking antipsychotics, $48 \%$ were taking antidepressants, and $7.3 \%$ were receiving hormonal therapy and most of them were receiving combination therapy with behavioural treatment. In this study, only $14.6 \%$ were taking cholinesterase inhibitors in combination with other therapies. In most of these subjects, behavioural therapy or combined behavioural and pharmacological therapy was started at the time of behaviour, whereas in some patients the previous drugs they were taking before this behaviour were continued if the physician found that to be appropriate.

Health professionals who are involved in the care of demented elderly patients should be educated through regular in-service training to prepare them to handle sexual inappropriate behaviours. Policies and procedures for identifying and dealing with this behaviour should also be enacted.

The limitations of the study are that this is a retrospective chart review and it is a descriptive study. Most of these subjects are reported cases by the healthcare workers and it is possible that we may not be identifying all the subjects who had this problem as family caregivers may not report it as frequently as healthcare caregivers.

\section{CONCLUSION}

In this study, sexually inappropriate behaviour was seen in all stages of dementia including mild cognitive impairment, more commonly associated with subjects with vascular aetiology, and was as commonly seen in community dwelling subjects with dementia as in nursing home subjects. Sexually inappropriate behaviour is one of the most difficult behaviours to manage for both informal and formal caregivers. Healthcare providers including those serving in the community must be educated to manage this condition.

\section{Authors' affiliations}

K Alagiakrishnan, D Lim, Division of Geriatric Medicine, Department of Medicine, University of Alberta, Edmonton, Canada

A Brahim, Department of Psychiatry, Alberta Hospital, Edmonton, Canada

A Wong, LongTerm Care Psychiatry Services, Edmonton, Canada A Wood, Geriatric Psychiatry Service, Edmonton Mental Health Clinic, Edmonton, Canada

A Senthilselvan, Department of Statistics and Epidemiology, University of Alberta

W T Chimich, L Kagan, Department of Psychiatry, University of Alberta Funding: none.

Conflicts of interest: none declared.

\section{REFERENCES}

1 Stern $Y$, Mayeux R, Sano M, et al. Predictors of disease course in patients with probable Alzheimer's disease. Neurology 1987;37:1649-53.

2 Beck C, Frank L, Chumbler NR, et al. Correlates of disruptive behavior in severely cognitively impaired nursing home residents. Gerontologist 1998;38:189-98.

3 Levisky ML, Owens JN. Pharmacologic treatment of hypersexuality and paraphilias in nursing home residents. J Am Geriatr Soc 1999;47:231-4.

4 Tsai SJ, Hwang JP, Yang CH, et al. Inappropriate sexual behaviors in dementia: a preliminary report. Alzheimer Dis Assoc Dis 1999;13:60-2.

5 Nagaratnam N, Gayagay G Jr. Hypersexuality in nursing care facilities-a descriptive study. Arch Gerontol Geriatr 2002;35:195-203.

6 Zeiss AM, Davies HD, Tinklenberg JR. An observational study of sexual behavior in demented male patients. J Gerontol A Biol Sci Med Sci 1996;51:M325-9.

7 Bozolla FG, Gorelick PB, Freels S. Personality changes in Alzheimer's disease. Arch Neurol 1992;49:297-300.

8 Devanand DP, Brockington CD, Moody BJ. Behavioral syndromes in Alzheimer's disease. Int Psychogeriatr 1992;4(suppl): 161-84.

9 Burns A, Jacoby R, Levy R. Psychiatric phenomena in Alzheimer's disease. IV; disorders of behavior. Br J Psychiatry 1990;157:86-94. 
10 Deanna DP, Levy SR. Neuroleptic treatment of agitation and psychosis in dementia. J Geriatr Psychiatry Neurol 1995;8(suppl 1):S18-27.

11 Auchus AP, Bissey-Black C. Pilot study of haloperidol, fluoxetine, and placebo for agitation in Alzheimer's disease. J Neuropsychiatry Clin Neurosci 1997:9:591-3.

12 Amadeo M. Antiandrogen treatment of aggressivity in men suffering from dementia. J Geriatr Psychiatry Neurol 1996;9:142-5.
13 Cooper AJ. Medroxyprogesterone acetate (MPA) treatment of sexually acting out. J Clin Psychiatry 1987;48:368-70.

14 Wiseman SV, McAuley JW, Freindenberg GR, et al. Hypersexuality in patients with dementia: possible response to cimetidine. Neurology 2000;54:2024.

15 Alagiakrishnan K, Sclater A, Robertson D. Role of cholinesterase inhibitor in the management of sexual aggression in an elderly demented women. J Am Geriatr Soc 2003;51:1326.

\section{Clinical Evidence - Call for contributors}

Clinical Evidence is a regularly updated evidence-based journal available worldwide both as a paper version and on the internet. Clinical Evidence needs to recruit a number of new contributors. Contributors are healthcare professionals or epidemiologists with experience in evidence-based medicine and the ability to write in a concise and structured way.

Areas for which we are currently seeking authors:

- Child health: nocturnal enuresis

- Eye disorders: bacterial conjunctivitis

- Male health: prostate cancer (metastatic)

- Women's health: pre-menstrual syndrome; pyelonephritis in non-pregnant women

However, we are always looking for others, so do not let this list discourage you.

Being a contributor involves:

- Selecting from a validated, screened search (performed by in-house Information Specialists) epidemiologically sound studies for inclusion.

- Documenting your decisions about which studies to include on an inclusion and exclusion form, which we keep on file.

- Writing the text to a highly structured template (about 1500-3000 words), using evidence from the final studies chosen, within 8-10 weeks of receiving the literature search.

- Working with Clinical Evidence editors to ensure that the final text meets epidemiological and style standards.

- Updating the text every six months using any new, sound evidence that becomes available. The Clinical Evidence in-house team will conduct the searches for contributors; your task is simply to filter out high quality studies and incorporate them in the existing text.

- To expand the topic to include a new question about once every 12-18 months.

If you would like to become a contributor for Clinical Evidence or require more information about what this involves please send your contact details and a copy of your CV, clearly stating the clinical area you are interested in, to Klara Brunnhuber (kbrunnhuber@ bmigroup.com).

\section{Call for peer reviewers}

Clinical Evidence also needs to recruit a number of new peer reviewers specifically with an interest in the clinical areas stated above, and also others related to general practice. Peer reviewers are healthcare professionals or epidemiologists with experience in evidence-based medicine. As a peer reviewer you would be asked for your views on the clinical relevance, validity, and accessibility of specific topics within the journal, and their usefulness to the intended audience (international generalists and healthcare professionals, possibly with limited statistical knowledge). Topics are usually 1500-3000 words in length and we would ask you to review between 2-5 topics per year. The peer review process takes place throughout the year, and our turnaround time for each review is ideally 10-14 days.

If you are interested in becoming a peer reviewer for Clinical Evidence, please complete the peer review questionnaire at www.clinicalevidence.com or contact Klara Brunnhuber (kbrunnhuber@bmigroup.com). 